\title{
Identidades em movimento: \\ uma etnografia em contexto de violência
}

DOI

http://dx.doi.org/10.11606/ 2179-0892.ra.2017.141651

\section{Aline Gama e Clarice Peixoto}

Universidade do Estado do Rio de Janeiro / Rio de Janeiro, RJ, Brasil

$\checkmark$ agamarj@gmail.com,cpeixoto@uerj.br

\section{RESUMO}

O trabalho analisa alguns movimentos em que as identidades na pesquisa com familiares de vítimas da violência do Rio de Janeiro acionam códigos de conduta ético-morais. A partir de observação participante, entrevistas e outras informações obtidas no campo, realizado entre 2009 e 2013, discutimos a relação intersubjetiva do antropólogo e a do familiar de vítima baseada no debate contemporâneo sobre identidade e alteridade. No campo, essas identidades se elaboram para superar o sofrimento individual dos familiares de vítimas em prol de causas coletivas, mas não é apenas ele que se converte em uma luta coletiva contra a violência, a partir do noticiário midiático. Guardados os devidos graus de envolvimento, o sofrimento dos familiares aciona outros como de pesquisadores, leitores e instituições que se inscrevem em uma linguagem e uma sociabilidade violentas. Entretanto, nesse trânsito identitário em situação limite pode-se perceber o surgimento de negações e do "duplo" sujeito/agente da violência urbana. 


\section{$1^{0}$ MOVIMENTO-IDENTIDADES POSSÍVEIS DO “ESTAR LÁ”...}

A partir da etnografia com familiares de vítimas do Rio de Janeiro, em movimentos sociais contra a violência urbana, analiso como as identidades de alguns familiares de vítimas são elaboradas e reelaboradas após a perda violenta de um ente. No momento de delinear algumas definições do campo como, por exemplo, quem seriam os familiares, onde encontrá-los e como transformar o encontro em um campo etnográfico fui interpelada pelo noticiário do dia 27 de fevereiro de 2009, que informava que André Azevedo, fotojornalista do jornal 0 Dia fora assaltado na Avenida Brasil e morrera na hora. AZ, como era conhecido, cobria os acontecimentos de violência na cidade. ${ }^{2}$

Esse acontecimento distante do espaço da cidade que eu transitava foi transformado pelos meios de comunicação de massa e pelas minhas preocupações em algo além daquilo apontado por Velho (1978) como "familiar". O "familiar", em teoria, seria a frequência com que recebemos o noticiário da violência urbana no Rio e nisso nada havia de estranho. Já o "exótico" ou o estranho surge pelo caráter inédito da inserção imediata da notícia na pesquisa de campo que ainda se constituía. Dessa forma, a relatividade das noções de "familiar" e "exótico" passa a ser constantemente reiterada como característica teórico-metodológica da pesquisa, uma vez que "o que sempre vemos e encontramos pode ser familiar, mas não é necessariamente conhecido, e o que não vemos e encontramos pode ser exótico, mas, até certo ponto, conhecido" (Velho, 1978: 39).

Nesse sentido, mais que informar sobre uma nova morte no Rio de Janeiro, o noticiário trouxe também a constatação de como seria complexo estudar a violência urbana em meio à permanência da violência. A violência da morte de $A Z$, um provável informante que conhecera através de amigos, desafiava o planejamento de etapas futuras e isso envolvia as vidas dos que direta ou indiretamente participavam da pesquisa. A morte violenta apresentava o risco como uma categoria elementar do fenômeno da violência.

Assim, diante do quadro de violência que não escolhe nem dia, nem hora, como planejar uma etnografia? O que aconteceria com as pessoas relacionadas à elaboração da pesquisa e com os outros interlocutores que lidam diariamente com a violência na cidade?

O questionamento ia além da discussão sobre as fronteiras entre nativos e antropólogos, os limites da subjetividade ou da afetação tratados por diferentes pesquisadores ${ }^{3}$. A rotina e a permanência de violência na cidade desafiavam e desafiam, ainda hoje, os projetos de pesquisa nesse campo, evidenciando que o imponderável da violência urbana deve se inserir não só na compreensão do fenômeno, mas também na dinâmica da produção de conhecimento sobre ele.

O recorte delimitado por familiares de vítimas de crimes de latrocínio e ho-
1 Este texto apresenta dados e análises da pesquisa de doutoramento, financiada pelo edital MCT/CNPq No 70/2008, desenvolvida no GP Imagens, Narrativas e Práticas Culturais (Inarra) do CNPq, PPCIS/ UER], orientada pela coautora Clarice Peixoto. A etnografia foi realizada por Aline Cama, tendo Clarice Peixoto como interlocutora nas reflexões sobre o campo e inspirações teóricas. Por isso, o texto flutua entre a primeira pessoa do singulare a do plural. A revisão de literatura foi fomentada pela bolsa de Pós-Doutorado do Programa Nacional de Pós-Doutorado PNPD/CAPES no PPCCISH/ UERN. Agradecemos às contribuições dos pareceristas anônimos da Revista de Antropologia

2 Ele foi um dos primeiros fotojornalistas a tomar conhecimento da pesquisa.

3 Apesar de diferentes autores da antropologia contemporânea tratarem da questão, refiro-me especificamente aos trabalhos de Viveiros de Castro (2002) e Favret-Saada (2005). 
micídios ${ }^{4}$, noticiados pela imprensa escrita, fazia parte da "linguagem da violência" e da "sociabilidade violenta", como conceituados por Silva (2011). No entanto, só parecia entrar no meu cotidiano quando em contato com o noticiário divulgado na mídia ou com amigos e familiares de vítimas. Esse contato circunscreve as fronteiras identitárias que são trabalhadas ao longo do tempo e tratadas nesse texto. O fluxo de movimentos acompanha a dinâmica do processo de pesquisa e das identidades de familiar de vítima e de pesquisadora inseridas na "sociabilidade violenta" da cidade do Rio de Janeiro. Tal sociabilidade

(...) se produz e reproduz a través das a tividades de atores competentes, conhecedores ativos, críticos e estratégicos, dessa forma de vida, que se conduzem de uma forma adequada. Entretanto, se eles podem ser conceptualizados como sujeitos, na acepção plena desta palavra, é um problema em aberto. Wieviorka (2005), por exemplo, denomina de antissujeito um tipo social não exatamente idêntico, mas próximo aos atores da sociabilidade violenta. O prefixo, porém, me parece canhestro e um tanto etnocêntrico, pois, no caso aqui tratado, aplica-se a atores que, a rigor, não são "anti" nada; somos nós, que operamos na linguagem da "violência urbana", que nos posicionamos contra sua forma de vida, não importa se com ou sem razão (Silva, 2011: 72). ${ }^{5}$

Se a "linguagem da violência urbana" constitui um conjunto fragmentado de discursos de distintas origens, tais como as das vítimas, dos criminosos, da mídia, de "pessoas comuns", das instituições públicas e de nós, cientistas sociais, com seus respectivos conteúdos que atribuem sentido às mais diversas práticas sociais no contexto de violência, a inserção nesse universo exige do pesquisador a identificação das ameaças à continuidade das etapas da pesquisa.

Assim, as tentativas de inserção no campo passam pelas diferentes possibilidades de comunicação da cidade do Rio de Janeiro e pelo agenciamento de uma linguagem da violência que se inscreve nos discursos orais e textuais, imagens, gestos e emoções.

Os jornais locais da cidade informavam sobre as novas violências, fornecendo o nome de novos familiares de vítimas, bem como de coordenadores de ONGs e movimentos sociais, além dos locais e datas das manifestações. Nas redes sociais Orkut e Facebook, encontrei os principais ativistas dos movimentos e alguns familiares, mas esses não foram simples meios de acesso aos informantes. Em vez de simplesmente reagirem às minhas ações, suas respostas pareciam se basear em expectativas geradas a partir dos significados atribuídos ao meu acesso (Blumer, 1969; Coelho, 2013).

Como considerava que as relações online fossem todas parecidas, tratei essa inserção como uma extensão dos contatos online pré-existentes. Até que ao rom-
4 Os casos são: a morte de Gabriela Prado publicada a partir do dia 26 de março de 2003 no jornal O Globo; a morte de Daniel Duque Pittman (18 anos) na saída da boate Baronetti, na praça Nossa Senhora da Paz, em Ipanema, publicada nos jornais O Dia e O Clobo a partir do dia 29 de junho de 2008; a morte de Júlio Baptista Almeida da Silva (29 anos) por traficantes do Complexo do Alemão, publicada no jornal O Dia a partir do dia 16 de julho de 2009; a morte de Júlio Cesar Menezes, publicada pelo jornal Extra a pedido da família a partir de 20 de setembro de 2010; o ataque de policiais ao carro da família do juiz Marcelo Alexandrino da Costa Santos (39 anos), no qual ele, seu filho (11 anos) e sua enteada (8 anos) foram baleados e sobreviveram, publicado a partir do dia 3 de outubro de 2010 nos jornais 0 Dia e O Clobo; e o assassinato de doze adolescentes na Escola Tasso da Silveira, em Realengo, publicado nos jornais a partir do dia 8 de abril de 2011 nos jornais O Dia e O Globo.

5 Mantive a citação como no original, que está em português de Portugal. 
per uma rede de aceites de amizade percebi a minha inabilidade em lidar com a linguagem e os códigos desse universo que significavam trocas simbólicas, nas quais "likes", aceites e postagens eram meios para a construção de vínculos às redes de familiares e amigos bem como compreensão de seus valores. Como assinala Hine (2000: 8, tradução livre):

Nossas crenças sobre a Internet e quais são suas propriedades podem expandir a investigação como a crença Azande sobre bruxaria (Evans-Pritchard, 1937), a crença dos ingleses sobre a realeza (Strathern, 1992), o entendimento americano do sistema imunológico (Martin, 1994) ou qualquer outro tema etnográfico. Crenças sobre a Internet podem ter consequências importantes para os modos pelos quais nos relacionamos com a tecnologia e uns com os outros através dela.

A partir disso, os mais diferentes meios de comunicação como celular, e-mail, chat e contatos pessoais começaram a servir de instrumentos para o trabalho de campo. Como adverte Ceertz (2001: 45), "tudo o que dizemos, tudo o que fazemose até o simples cenário físico têm, ao mesmo tempo, que formar a substância de nossa vida pessoal e servir de grão para nosso moinho analítico."

Em outro momento, o celular, além de meio de comunicação, também se transformou em símbolo de troca pessoal. No período de recesso entre o Natal e o Ano Novo, a mãe de um adolescente assassinado telefonou perguntando se a operadora do meu celular era a mesma que a dela, e em caso positivo, que poderíamos usufruir do benefício de gratuidade. Na ocasião, ela estava fora do Rio de Janeiro e solicitou a minha mediação para resolver um problema. Esta parecia ser a porta aberta para aprofundar e ampliar o relacionamento com os familiares de vítimas.

No entanto, a ultrapassagem da porta ou dos limites imaginários desse universo, estava não só longe de significar qualquer conhecimento sobre quem eram os familiares de vítimas, como construíam essas identidades e se relacionavam com o fenômeno da violência, mas também todas as nuances possíveis de quem eu seria depois de "estar lá", como nas palavras precisas de Ceertz (2002: 38):

"Estar lá" em termos autorais, enfim, de maneira palpável na página, é um truque tão difícil quanto "estar lá" em pessoa, o que a final exige, no mínimo, pouco mais do que uma reserva de passagens e a permissão para desembarcar, a disposição de suportar uma certa dose de solidão, invasão de privacidade e desconforto físico, uma certa serenidade diante de excrescências corporais estranhas e febres inexplicáveis, a capacidade de permanecer imóvel para receber insultos artísticos, e o tipo de paciência necessária para sustentar uma busca interminável de agulhas invisiveis em palheiros invisiveis. 
A "permissão para desembarcar" significa reconhecer também, por exemplo, que para chegar em uma comunidade dominada pelo tráfico ou por milícias é preciso estar acompanhada de um morador ou trabalhador do comércio local para evitar constrangimentos. Outro exemplo seria o de perceber que muros e moradias estão perfurados por projéteis e evitar tecer comentários como demonstração de familiaridade com esses locais da cidade.

Nesse sentido, essa experiência ímpar de desconforto físico, emocional e social de acesso ao universo do fenômeno da violência urbana fica reduzida no texto escrito a uma seleção de palavras e ao registro de gestos. Se a realidade é inacessível à percepção, Goffman (1981) nos conforta ao afirmar que ela é de alguma forma passível de ser representada, compartilhada e compreendida socialmente. Ao mesmo tempo tal desconforto sobrepesa nessas representações por sua inscrição em nossa sensibilidade como um coautor raramente requerido no momento da escrita. ${ }^{6}$

Nos encontros e manifestações, a presença de uma pessoa estranha à rede de familiares de vítimas da violência sempre gera inquietação ${ }^{7}$. Em uma delas, na Candelária, enquanto os manifestantes organizavam faixas, cartazes e um varal com fotografias fui questionada pelo fato de estar próxima ao grupo. Não estava ali como o público que parava alguns segundos e passava e muito menos como os jornalistas que se aproximavam, entrevistavam, fotografavam e corriam para cobrir a próxima pauta.

-O que vocêfaz aqui? (...)

-Sou pesquisadora.

-De onde?

-Da UERJ, de Ciências Sociais.

- Conhece o professor Ignácio Cano?

- Conheço, mas não sou aluna dele, não.

- Vira e mexe ele fala nos jornais.

-É, eu sei, mas eu trabalho com fotografia e minha pesquisa é sobre imagens de violência.

A pergunta veio como um aviso. O questionamento do manifestante não era um "ato desinteressado", mas repleto de sentidos que estabeleceriam o grau da interação e o tipo de relacionamento que teria com o grupo. $O$ fato de me apresentar como pesquisadora (com caneta, bloco e celular na mão) não era o suficiente. A instituição da pesquisa e as relações profissionais eram as principais referências para me situarem em algum lugar no universo dos pesquisadores da violência no Rio de Janeiro. Nesse primeiro contato, trava-se um jogo de representações entre os participantes do grupo, suas expectativas sobre as pessoas externas a
6 Refiro-me à discussão proposta por Clifford Geertz sobre o caráter interpretativo da escrita etnográfica, também presente nos textos reunidos por Clifford e Marcus (1986). Ver, principalmente, a análise de Sardan (1996) que aponta as fronteiras epistemológicas da interpretação.

7 As manifestações que participei ocorreram em vários bairros da cidade do Rio de Janeiro: na Cinelândia e em frente à igreja da Candelária, no Centro do Rio de Janeiro; na praia de Copacabana; na praça São Francisco Xavier e no largo da Segunda-Feira (Tijuca), na Cidade Alta (Cordovil) e em Realengo. Já os encontros caracterizados por um grupo restrito de familiares e amigos foram organizados tanto para as exibições dos documentários "Luto como mãe", de Luiz Carlos Nascimento; "Estrada", de Aude Chevalier-Beaumel; e "Lembrarpara não esquecer - Vigário Ceral", de Milton Alencar Júnior, quanto para a diferentes comemorações como o Dia do Amigo, o Dia das Crianças etc. (realizadas nas casas de mães das vítimas da Chacina de Realengo). 
ele, os externos a eles sobre si e sobre eles, além deles próprios a partir desse reconhecimento de ativistas/familiares de vítimas da violência (Coffman, 1975).

Além de uma definição de papéis e, respectivas identidades, o diálogo também mostra uma linguagem gestual da violência e da "sociabilidade violenta". Os coordenadores e familiares mais antigos sempre "ficam de olho" em quem está na manifestação, pois após a perda violenta do ente os familiares de vítimas muitas vezes encontram testemunhas e culpados. Alguns deles tentam coagir familiares e coordenadores fazendo ameaças de morte.

Essa definição de papéis/identidades pode ser percebida dentro das perspectivas de Erving Coffman e Stuart Hall. A construção das identidades na pesquisa possui alguns aspectos que se sobressaem nos momentos de contato, ou de "frontstage", como esse, em que fui indagada pelo grupo ${ }^{8}$. A cada novo contato com novos familiares mais uma indagação sobre o que estava fazendo entre eles e as razões de meu interesse até que como um "blues, cuja melodia ganha força pela repetição das suas frases de modo a cada vez mais se tornar perceptível" (DaMatta, 1978: 29), eu estava lá.

As identidades, como veremos ao longo do texto, são elaboradas e reelaboradas na longa via-crúcis dos familiares após a morte violenta do ente e constituem-se como uma das identificações que os familiares assumem, entre outras tantas formuladas ao longo da vida (Hall e Gay, 2003 e Hall, 2000). Como afirma S. Hall (2000:13), a identidade é:

\section{(...) formada e transformada continuamente em relação às formas pelas quais} somos representados ou interpelados nos sistemas culturais que nos rodeiam. Édefinida historicamente, e não biologicamente. O sujeito assume identidades diferentes em diferentes momentos, identidades que não são unificadas ao redor de um "eu" coerente. Dentro de nós há identidades contraditórias, empurrando em diferentes direções, de tal modo que nossas identificações estão sendo continuamente deslocadas. Se sentimos que temos uma identidade unificada desde o nascimento a té a morte é apenas porque construímos uma cômoda estória sobre nós mesmos ou uma confortadora "narrativa do eu".

É a partir dessas "narrativas do eu" coletadas durante as entrevistas 9 e da observação participante que o fenômeno da violência urbana no Rio de Janeiro será analisado, no intuito de responder: quem são esses familiares que se definem a partir da vítima? Como enfrentam a ausência e a superação? E como são escolhidos no noticiário para serem casos exemplares da violência urbana?

Através do noticiário temos acesso aos acontecimentos da cidade e dessa "construção simbólica" que definimos como violência urbana, apoiadas na perspectiva de Silva (2016: 191). Essa construção possui um significado instrumental
8 Rocha \& Eckert (1998) analisam a identidade narrativa do antropólogo no processo de construção do conhecimento antropológico e apontam para a exigência de "um quadro de referência diferente" para a produção antropológica contemporânea, tal como proposto por George Marcus: "um projeto de auto-identidade que ainda não se completou ou que talvez não seja possível completar".

9 Nesta pesquisa foram entrevistados os editoreschefes de fotografia, alguns fotojornalistas e doze familiares de vítimas (pais, mães, irmãs e tias) dos casos analisados, sendo que dois deles são os coordenadores dos movimentos Gabriela Sou da Paz e Associação de Familiares e Amigos dos Anjos de Realengo. 
e cognitivo a partir dos quais se "destaca e recorta aspectos das relações sociais que os agentes consideram relevantes, em função dos quais constroem o sentido e orientam suas ações". Dessa forma, no segundo movimento do processo de pesquisa destacam-se aspectos dessas relações sociais inerentes à dinâmica da produção do noticiário dos casos analisados.

\section{$2^{\circ}$ MOVIMENTO-IDENTIDADES MEDIADAS}

Definir e identificar quais violências ou familiares de vítima são noticiáveis é bastante polêmico. Importância, atualidade e interesse humano são características que norteiam as análises de diferentes autores. Lage (1982) define "notícia como o rela to de uma série de fatos a partir do fato mais importante", e este possui dois componentes básicos: o componente lógico com uma organização relativamente estável, em referência ao lide; e o componente ideológico "escolhido segundo critérios de valor" (Lage, 1982: 34). Já para Sodré e Ferrari, "notícia é todo fato social destacado em função de sua atualidade, interesse e comunicabilidade" (Sodré e Ferrari, 1982: 7). Para se transformar em notícia, o fato romperia com a rotina ou com a normalidade (Paiva, 2005), seguindo a ideia de Amos ]. Cummings, quando este diz que "se um cachorro morde um homem, não é notícia; mas se um homem morde um cachorro, isso é notícia."

Todas essas definições fundamentam a produção e a escolha do conteúdo do texto e da fotografia de uma notícia. Nesse contexto, o trabalho dos autores (repórteres de texto e imagem) pretende aumentar a venda/distribuição, alimentando a curiosidade do leitor/comprador. No entanto, "as notícias são fruto das dinâmicas e dos constrangimentos do sistema social, particularmente do meio organizacional, em que foram construídas e fabricadas" (Souza, 1999: 6). Esses constrangimentos ocorrem seja entre repórteres (de diferentes empresas ou da mesma) que trocam informações sobre o acontecimento, seja entre editores e repórteres ou entre editores e chefes de redação que hierarquicamente negociam a cobertura e a publicação, seja entre instituições públicas e repórteres que agenciam discursos, ou ainda entre fontes de informação e repórteres. A produção e a publicação de uma notícia envolvem muitos agentes sociais e inúmeras possibilidades de negociação.

Dessa forma, a relação com a alteridade é intrínseca à ação profissional do fotojornalista. A produção da imagem fotográfica "obedece a protocolos" e a ausência de sofrimento com a violência vivenciada durante o trabalho é percebida como uma manifestação de frieza e desumanidade e foi relatada por todos os fotojornalistas entrevistados. O "normal", de acordo com os entrevistados, é a "expressão obriga tória dos sentimentos" que se manifesta através de uma emoção, que deve ser contida para não interferir no sofrimento dos familiares da vítima 
e, tampouco, na rotina de trabalho dos demais colegas que também registram o acontecimento.

Nas situações em que o corpo não está mais no local, ou de uma violência extrema, o acontecimento não é registrado fotograficamente a pedido ou em respeito à família. Nesse caso, os fotógrafos, "com muito jeito", solicitam aos familiares uma fotografia da vítima ou um documento para ser publicado no jornal. Quando não conseguem e, sendo o caso considerado importante, eles procuram os perfis da vítima nas redes sociais online e publicam com ou sem o consentimento dos familiares. Trata-se de mostrar "quem foi a vítima" e de aproximá-la dos leitores para que estes relacionem o ato violento descrito no texto da notícia com a imagem da vítima ainda em vida.

O acontecimento da violência se transforma, então, em espetáculo que se acompanha e se repete nos jornais, na televisão e na internet. Nesses veículos, a notícia inicia para leitores/espectadores e familiares uma via-crúcis na busca por justiça e reparação. Os relatos das testemunhas, as informações analíticas de muito ou pouco sofrimento da vítima e as reações de familiares, vizinhos, amigos e instituições públicas denunciam em detalhes no noticiário as violências cometidas na cidade. Como parte do trabalho de ativistas nas causas da luta contra a violência, os familiares de vítimas antigas se solidarizavam com os novos familiares, participando dos velórios e missas de sétimo dia para prestar seu apoio e repúdio à situação em que mais uma família estava envolvida.

Essa aproximação faz parte da rotina daqueles que sofreram com a violência e se constituem como um novo "meio social" dos familiares que acabaram de perder um ente. Esse "meio socialé melhor compreendido, não como a área em que vive a família", o local em que aconteceu a violência ou estejam inseridos criminosos, instituições públicas, profissionais da mídia e vítimas em diferentes graus, "mas sim, como a rede das relações sociais reais que elas mantêm (...)" (Bott, 1976: 111), ou passam a manter após a violência.

A inserção dos familiares de vítimas nessa rede é um processo que remete às perspectivas de análise da violência sugeridas por Wierviorka (2005), na qual se diferencia "violência" e "conflito". Para ele, mesmo que o conflito possa eventualmente utilizar-se de alguns meios violentos, a violência interrompe a continuidade do conflito e, assim, impede o desenvolvimento da sociabilidade. Sem minimizar a dificuldade de limitar as fronteiras entre um e outro, chamo atenção para o segundo momento dos casos analisados nessa pesquisa, nos quais após a "violência original" surge um território de disputas em diferentes níveis, permitindo perceber um processo de reinscrição tanto da "linguagem da violência" quanto da "sociabilidade violenta" que vislumbra, de forma talvez contraditória, a interrupção dos conflitos com a solução do caso na justiça.

Nesse processo de reinscrição ou da reelaboração da violência, os familia- 
res transitam entre sujeitos e agentes dessa sociabilidade. A transformação da perda violenta de um familiar em uma causa coletiva não é fato comum a todas as famílias, tampouco é uma consequência imediata do noticiário sobre os casos. Ao acompanhar os jornais locais e frequentar os eventos contra a violência, percebi que a manifestação coletiva de alguns destes casos acontecia imediatamente após a violência sob orientação da coordenação das ONGs e demais familiares/ativistas. No entanto, a permanência como ativistas da causa os insere em uma situação liminar de agenciamento da sua condição, operando um jogo de visibilidade e invisibilidade. Assim, as denúncias públicas veiculadas pela mídia e as manifestações inscrevem não só acionamentos políticos, mas também formas de proteção.

Essas mortes tornadas públicas ou mediadas por jornais impressos, televisivos e online têm suas convenções e, entre elas, se destacam a imagem do sofrimento dos familiares das vítimas. Esse sofrimento público se articula entre uma "política da piedade" e uma "política da justiça" (Boltanski, 1993: 15-17), que se distinguem em três aspectos. O primeiro é que uma sociedade orientada pela justiça não opõe felizes e infelizes, grandes e pequenos, pois considera apenas o valor justo. O segundo é o fato de que ser grande ou pequeno não define uma condição para justiça. $O$ terceiro é que em consequência da não ligação das qualidades às pessoas, a justiça atua sob a convenção de equivalência das provas confrontadas com a realidade. Já em uma sociedade orientada pela "política da piedade", a urgência da ação é promovida para estancar o sofrimento invocado e este sempre triunfa sobre a consideração da justiça.

Diante da perda de um ente querido, a publicação do fato nos jornais é vista pelos familiares como "a única forma deles terem alguma voz", pois consideram o sistema de justiça "lento e ineficaz". Os familiares aceitam o trabalho da mídia, supondo que ela tem mais poder de ajudá-los na busca por uma solução mais rápida a favor de uma política identitária. Em um caso, a irmã da vítima foi à Secretaria de Segurança Pública para solicitar a busca do corpo do irmão morto. Na conversa, Bernadete ${ }^{10}$, a irmã, recebeu como contraproposta realizar uma campanha para localização de cemitérios clandestinos em parceria com a mídia. Nas palavras dela:

Eles disseram: vocês entram em contato com a mídia e nós faremos uma campanha lá na comunidade. Aí eu falei: acontece que a mídia não está mais interessada no caso do meu irmão. Todo dia aparecem casos novos. Então, está começando a cair no esquecimento. Acho que é perda de tempo. [Bernadete segue relatando o diálogo:] - Mas a Secretaria de Segurança tem a parte de divulgação e de marketing. - Se for da iniciativa de vocês, eu acho que teria mais credibilidade, mas sei que não interessa.

10 As relações de parentesco são aquelas definidas pelos familiares de vítimas nas entrevistas e os seus nomes são fictícios. Os nomes das vítimas foram mantidos, uma vez que são publicizados nas mídias impressa e televisivas. 
- Nós vamos fazer uma parceria aí. Vai ter uma parceria com a TV Globo, masé aquilo, ainda não está certo. Nós vamos tentar conversar com o secretário para ver se ele vai lá.

Aí eu pensei: "Será que ele vai?" Aí começou...

A solicitação do direito de enterrar o corpo do irmão transformou-se em uma negociação com a mídia que durou três meses. Bernadete participava das reuniões entre a mídia e a Secretaria de Segurança Pública. O começo da campanha foi adiado para depois do Carnaval, em função das demais prioridades da cidade - Natal e Ano Novo-, mais importantes que encontrar um corpo desaparecido". Nas resoluções finais, Bernadete é avisada que teria que ir à comunidade para falar a TV Clobo e descreve:

Aí eu falei: "Perfeitamente, doutor". Quando eu saí de lá, nesse dia estava eu e minha irmã, que falou: "Vocêe maluca! Comoé que a gente vai lá? Só se for encapuzada". Eu disse que iria, mas tu achas que nós vamos? Deles estarem organizando e tentando fazer é uma coisa, disso ser realizado (...).

Foi o que aconteceu. Na véspera do dia marcado me ligaram da TV Globo: "olha, Dona Bernadete, vai ter a matéria amanhã. O Secretário vai e vocês vão ter que ir lá". E eu falei: "Nós não vamos, nós repensamos (...). Nós estamos apreensivas, minha mãe já tem idade. Vamos fazer o seguinte, nós vamos fazer a matéria sem ser lá e na hora vocês editam". (...)

Bernadete continua relatando a conversa com o repórter:

A inicia tiva partiu deles e agora quem dá as coordenadas sou eu. A Secretaria de Segurança Pública está interessada para limpar a imagem dela. Então, não sou burra, não.

Quando eu vi o Secretário com panfleto na mão, com a foto do meu irmão, eu pensei: "Pô, ele nunca atendeu a gente". Era sempre o sub. Sub isso, sub aquilo. Você nunca fala com o titular, mas ele foi lá, com o panfleto e tudo mais.

O relato de Bernadete apresenta diversas marcas de sua competência, no sentido dado por Boltanski (1990), em articular os interesses da mídia e da Secretaria de Segurança a favor do caso de seu irmão. No momento em que a Secretaria propõe que Bernadete procure os jornalistas, ela expõe questões do relacionamento entre familiares de vítimas e a mídia, conseguindo inverter o papel de solicitante da cobertura. Em suas considerações a respeito da situação em que se envolvera, Bernadete apresenta o trânsito hierárquico da negociação, os argumentos e as estratégias que usou.
11 A condição de desaparecimento é discutida por Letícia Ferreira (2011, p.277) que considera que "o "problema social" do desaparecimento é construído a partir da denúncia pública de múltiplas faltas que, somadas, parecem conferir àquela ausência uma importância e gravidade que Ihe é rotineiramente negada". 
No primeiro instante, ela atua como se permitisse que os representantes do Secretário de Segurança conquistassem uma posição de superioridade. Seu relato exprime consciência da representação de relação assimétrica, marcada pela fala "Perfeitamente, doutor", na qual ela acata as ordens. A consciência da representação é revelada quando ela é questionada, em seguida, por sua irmã. Apresenta, então, sua estratégia para as pessoas da secretaria continuarem a trabalhar na produção da ação.

Nos instantes próximos, quando todos já estavam comprometidos com o Secretário de Segurança, Bernadete inverte a hierarquia, tem em suas mãos o poder de negociação. Para isso, baseia-se em todo o conhecimento acumulado durante as entrevistas sobre o caso de seu irmão. A possibilidade de edição, vista por Bernadete como um trabalho ruim da mídia, que diminuía seu poder de fala e argumentação, passa a ser usada a seu favor.

A mediação pelos jornais apresenta diferentes aspectos das relações que os familiares estabelecem durante a produção de notícias sobre o caso. Interessam nesse trabalho as estratégias usadas pela mídia como mediadora não só entre leitores ou espectadores e acontecimento, mas também entre instituições públicas e familiares de vítimas, que precisam desenvolver competências para lidar com essa mediação. Nela se identificam familiares, instituições, personalidades públicas envolvidas, vítimas, suspeitos e jornais como uma instância autorizada pelas partes para falar a respeito do caso e da situação de violência na cidade. Isto é, não é só o sofrimento individual que se converte em uma luta coletiva contra a violência, como analisou Boltanski (1993), mas também suas identidades de familiares de vítimas são agenciadas em relação axial com uma política de situação em prol de uma causa e os transformam em pessoas-símbolos contra violência que são acionadas pelo coletivo (mídia, movimentos sociais e novos familiares de vítimas - nessa "ordem") no momento em que novas violências são publicadas no noticiário.

Dessa forma, a exposição do sofrimento das "mortes matadas" no Rio de Janeiro, é ao mesmo tempo matéria-prima e engrenagem das ações individuais que se transformam em espaço de lutas públicas. Essas ações foram expressas pelos familiares entrevistados pelo termo "luta", uma categoria que aponta para uma luta política que por sua vez é intrínseca à luta pessoal de forma polissêmica (Comerford, 1999). A "luta" sintetiza a rotina da vida e seus afazeres cotidianos, sempre marcados pelas lembranças dos entes, em meio aos conflitos junto à burocracia estatal para conseguir os direitos à reparação e à condenação dos culpados. Paralela a essa nova rotina, alguns familiares convertem suas lutas pessoais em uma luta pública na qual expõem sua dor como forma de mobilização coletiva para, de um lado, pressionarem o governo a criar políticas de segurança pública ${ }^{12}$ e, de outro, protegerem-se de retaliações dos suspeitos do caso. 
Como aponta Das (2007), aqueles que sofreram com a violência precisam se autorreconstruir. Suas identidades de familiares atravessam um processo de reelaboração a partir da perda violenta, expressas em gestos e ações nos quais é possível perceber as marcas da "violência original"13 em suas vidas.

\section{$3^{\circ}$ MOVIMENTO-IDENTIDADES DOS FAMILIARES}

As marcas da violência são códigos presentes no cotidiano dos familiares de vítimas que publicizaram suas perdas através dos noticiários e de ações nas manifestações contra violência. Em uma delas, duas mulheres cujas camisetas estampavam as fotografias de seus familiares assassinados conversavam baixinho sobre as outras pessoas que compareceriam à homenagem em frente à igreja da Candelária. Uma terceira mulher se aproximou e disse animadamente:

-Oi, tudo bem?

Elas se entreolharam e ela mesmo respondeu:

- Aliás, tudo bem eu sei que não tá!

As duas mulheres balançaram a cabeça afirmativamente, franzindo os olhose torcendo a boca, responderam apenas:

$-E_{\text {... }}$

- Mas a gente vai levando... -continuou.

-É... Fazer o quêe? A gente não tem mais opção mesmo-respondeu uma delas de cabeça baixa e mexendo no lenço de lágrimas.

- Mas não podemos deixar a peteca cair, não. Estamos aquié para lutar. Vocês viram a coordenadora? - Ela tenta a lentar as duas e mudou a direção da conversa.

Essa forma de cumprimentar, praticada em outros espaços sociais como bares, clubes e academias, possui nuances que são próprias do universo pesquisado. $\mathrm{O}$ tom da fala era uma apresentação de si para as duas mulheres que estavam sentadas, conversando. Entretanto, a apresentação divergia da expectativa das duas mulheres devido ao momento de homenagem às vítimas. Esse instante de divergência pode ser visto como uma falha naquilo que Coffman $(1975,1981)$ trata como um mecanismo de controle sobre como agir e o que falar na presença de outro.

As duas mulheres haviam perdido seus entes fazia pouco tempo. Já a terceira vivia outra etapa do processo emocional de lidar com a perda, pois participava de encontros de familiares de vítimas havia mais de cinco anos. Nesse processo, aqueles que transformam suas identidades em uma identidade coletiva acionam sua condição de familiar como uma autoridade moral que transita tanto entre o sofrimento individual para causas coletivas, como entre as causas que, ao se tornarem coletivas, reacendem a memória de seus sofrimentos
13 A expressão "violência original" é usada por Veena Das para se referir aos estupros sofridos por mulheres durante os conflitos de Partição da Índia. Usamos a expressão para referir ao momento em que os familiares tomam conhecimento da morte violenta de seus entes. 
individuais mesmo quando ao longo do tempo se reelaboram emocionalmente para lidar com a perda.

Entretanto, os familiares mais antigos que sofreram violência são considerados referência de como ser "familiar de vítima" e são convidados para falar para as novas famílias de vítimas. Isto é, há uma hierarquia no interior do grupo, na qual os familiares de vítimas mais recentes criam expectativas sobre a liderança, aqueles que participam do movimento há mais tempo. Esta situação nos remete a Mauss quando trata da responsabilização de agentes pela expressão coletiva do sentimento nos ritos orais funerários na Austrália. Ele escreve:

Não apenas o tempo e as condições da expressão coletiva dos sentimentos são fixados, mas também os agentes desta expressão, que não uivam e gritam unicamente para traduzir seu medo, sua cólera ou sua tristeza, mas porque são obrigados, encarregados de o fazer (Mauss, 1980: 59).

Há um saber que se refere ao tempo de participação de cada familiar no movimento e que envolve também atribuições de responsabilidade de como lidar com as emoções e como se expressar em cada situação. Por outro lado, os familiares que chegam também precisam caminhar para compreender os gestos e as linguagens desse universo. Em seu primeiro encontro com outros familiares e também com sobreviventes da violência no Rio de Janeiro, Eduardo, pai de uma vítima recente, diz ter se assustado quando ouviu as pessoas se apresentarem, perguntando: "Você tambémé da dor?"

As pessoas que estavam lá são ligadas a algum tipo de evento ruim. Assim, elas se identificavam como "você também é da dor?" Da dor! Nãoe e "doador", não. Você pertence à dor! Então, olha só como isso mancha as pessoas e você não consegue se desconectar mais dessa coisa e eu vi cada caso. Aquela menina da Estácio, cara, numa cadeira de rodas com um dreno na boca. Toda ruim, sabe?! A vida dela foi pro beleléu e a das pessoas ao redor dela também! Porra, quem arruma essa muIher? Quem dá banho nela? Quem leva ao banheiro? Quem tira a fralda? Quem alimenta? Éa vida de todo mundo, cara!

Sua fala apresenta dois aspectos do universo de familiares de vítimas. O primeiro é o de que a violência física, cometida diretamente sobre o corpo de alguém, atinge a vida e a rotina das pessoas mais próximas. O segundo é a construção de uma "mancha" na identidade dos familiares.

No exemplo, ele fala do caso de Luciana de Novaes, 28 anos, vítima de uma bala perdida que a deixou tetraplégica em 2003, e que precisa de atenção em tempo integral. Seus pais relatam a rotina de cuidados que exigem uma dedica- 
ção completa, desde a higiene e a alimentação até o acompanhamento de suas consultas com médicos e fisioterapeutas. Ou seja, a dor da violência sofrida é (re)vivida cotidianamente.

Os casos de homicídio também exigem enorme investimento emocional e material dos familiares e amigos da vítima. A perda violenta de um ente interfere em vários aspectos da vida e a transforma em uma via-crúcis que se caracteriza pela busca por justiça e reparação. Esse processo, por sua vez, se desdobra na expectativa de uma superação parcial da perda, a partir da qual algumas pessoas desenvolvem diferentes Transtornos de Estresse Pós-Traumático (TEPT), como analisados por Soares et al. (2006).

A "mancha", apontada por Eduardo, é sinônimo de um estigma, como proposto por Coffman (1988). Os familiares das vítimas passam a se ver e a serem vistos também como vítimas da violência ou "vítimas secundárias ou ocultas". A tentativa de superar a perda violenta, participando de encontros, missas e manifestações e, principalmente, expondo seus rostos e nomes na mídia, cria essa nova identidade que é a de alguém que sofre ou luta porque seu ente foi morto. A construção de uma identidade de familiar de vítima, que também é midiática, é corroborada por pais e mães que passam a ser identificados pela perda do seu ente. Eles passam a ser conhecidos como "o pai da Cabriela" ou "as mães de Acari".

Depois da experiência das consequências da violência, da relação com a mídia e com outros familiares, esse estatuto de familiar de vítima transforma-se na característica social mais relevante. Trata-se de designar algo "sobre um indivíduo, sobre suas características mais ou menos permanentes, em oposição a estados de espírito, sentimentos ou intenções que ele poderia ter num certo momento" (Goffman, 1988:

53). A presença deles é uma informação social e política. Suas imagens transformam-se em um símbolo da luta de familiares de vítimas contra a violência.

No entanto, os familiares do grupo que se transformaram em uma pessoa-símbolo da luta contra a violência na cidade do Rio de Janeiro reiteram a observação de Eduardo de que a espetacularização "mancha" a vida das pessoas. Para Marilene ${ }^{14}$, ela e o grupo de mães de Acari foram isoladas, deixaram de ser convidadas para churrascos de amigos e encontros de vizinhos por carregarem essa marca: "Somos as Mães de Acari. Para todo mundo nós somos pessoas tristes porque perdemos nossos filhos violentamente".

A mudança da sociabilidade, o olhar de pena e a falta de convites para reuniões com os amigos são percebidos, pelos familiares, como uma consequência desse estigma. A tristeza do luto que não foi vivida em um momento privado passa a interferir nas relações sociais independente de continuar a ser expressa publicamente, formando outras formas de isolamento.

É "o perder alguém violentamente" que estabelece o vínculo de reconhecimento de uma identificação que se constrói por uma "dor ímpar". São características
14 Único nome verdadeiro de todo texto. É uma homenagem póstuma a Marilene Lima de Souza, mãe de Rosana de Souza Santos que faleceu em outubro de 2012, em consequência de um tumor no cérebro. 
compartilhadas com outros familiares que criam uma rede de solidariedade e lealdade estabelecidas sobre uma dor que só conhece quem a viveu.

Ao longo do tempo, essas relações formam uma rede que se iniciou com a procura de apoio e solidariedade após a violência para superar a dor, buscar justiça e não deixar que o caso de seu familiar seja esquecido publicamente. Sob a forma de mobilizações públicas e de discursos visuais e verbais, a natureza emocional desse vínculo marca uma distinção entre aqueles que experimentaram a violência e o resto da população civil. Para Jimeno (2010: 99), "a linguagem do testemunho pessoal conforma comunidades no sentimento, por mim chamadas de comunidades emocionais, de moralidade, fundadas numa ética do reconhecimento".

Além de expressões dos sentimentos que pesam sobre a identidade desses familiares, encontrei, no grupo analisado, objetos pessoais e fotografias dos entes vitimados como forma de reter sua presença e manter ativa sua memória. Esses são transformados em objetos de culto familiar e público, mas para a família se soma um valor de continuidade.

As fotografias dos filhos saudáveis e felizes espalhadas pela casa são testemunhas oculares da existência de uma vida familiar. Os sorrisos, olhares, poses e penteados dos filhos emoldurados e expostos na sala de visitas, no visor de um celular ou na tela de um computador são expressão de permanente rememoração e, assim, de cristalização do grupo familiar original.

Essas fotografias expostas não são apenas homenagem ou lembrança, elas demarcam a presença e a relação de pertencimento à família a despeito da violência da morte. Isto é, reafirmam o vínculo familiar construído ao longo do tempo de vida em comum. Como afirma Moreira Leite (2001: 44), "o tempo fotográfico recompõe o tempo da memória, alheio ao tempo cronológico. São instantâneos irregulares e arbitrários ligados e separados pelo esquecimento". As fotografias demarcam a continuidade de suas existências na vida familiar, simbolizando um prolongamento das construções identitária dos membros dessas famílias que não foram destruídas junto com a morte.

As atribuições e os sentimentos diferem em cada membro da família, pois constroem as identidades de cada um. Ao longo das etapas da vida, as identidades sofrem constantes transformações em que a família se estabelece "(...) como uma entidade unida, integrada, unitária, logo, estável, constante, indiferente às flutuações dos sentimentos individuais" (Bourdieu, 1996: 129). Os pais, irmãos, tias e avós dos entes mortos são seus familiares a partir de seus primeiros instantes de vida. Esse "ser" familiar de alguém foi elaborado e reelaborado ao longo da vida.

O futuro daquele que continua vivo não é o esquecimento. Os familiares tentam de diferentes maneiras refazer o espaço simbólico dessas relações. " $O$ trabalho de lu to separa definitivamente o passado do presente e abre espaço ao futuro." (Ricoeur, 2007: 506). O ente que morre violentamente, o filho, neto ou sobrinho 
que se torna abruptamente ausente, ganha outra forma de presença. Essa nova presença ecoa da construção identitária relacional e da manutenção do grupo familiar. A presença em fotografia, mais que afirmar a existência de um outro do lado de fora, produz um trabalho performativo de constante rememoração, revelando a identidade de cada um dos familiares com os seus entes mortos, pois é ela que os constitui.

As falas das mães reconhecem tudo aquilo que as fizeram e as fazem mães das vítimas: dos primeiros dias da gravidez à notícia e experiência de sua morte, até os dias atuais, quando elas reconhecem que as fotografias, as conversas e as relações familiares os mantém presentes em suas vidas (Beauvoir, 1967 e Young, 2005). Dessa forma, é possível pensar que as diferentes identidades destes familiares encontraram meios de sobreviver à morte.

Essas identidades são elaboradas para o coletivo como representantes do familiar que se foi e, também, de determinado grupo ou causa que surgiu a partir da "violência original". Ela é, assim, retomada pelo grupo não só pela ideia de uma identidade homogênea, mas também, pela concepção de família construída ao longo do século XVIII. Nessa ideia centrada na noção de indivíduo, a família é entendida como um conjunto de indivíduos reunidos por laços contratuais e de sangue, como apontou Ariès (1977), mas também na ideia da construção de sentido de uma mutualidade, discutidos por Carsten (2004) e Sahlins (2013). Isto é, o sofrimento demonstra que suas existências e identidades são intrínsecas e que o que foi vivido por um familiar os demais também vivenciam.

No entanto, nessa situação limite, surgem movimentos de negação ou de questionamento de identidades em diferentes situações, como Lucia indaga: "Existe um nome para um pai ou uma mãe que perdeu um filho? Existe, me diz? Então, o que sou eu? Como é que eu me chamo?".

A condição de mãe de vítimas transforma-se em um elemento de autoridade moral em diferentes contextos (Vianna e Farias, 2011). Os relatos redimensionam a intensidade da dor, sendo a dor da mãe a maior delas dado que o filho simboliza parte de seu corpo; a seguir vem a dor do pai, depois a dos irmãos, tios e avós. Entretanto, em alguns casos, a figura da mãe não surge apenas no vínculo biológico, mas naqueles estabelecidos pelo cuidado e pelo afeto. $O$ sentimento de pertencimento, no qual "não importa se ele é ou não ésangue do meu sangue", como afirmou uma mãe, é adquirido por viverem na mesma casa apesar da inexistência de laços de procriação sexual (Carsten, 2004).

A falta de definição ou de adjetivo para os pais que perderam seus filhos é comparada à definiç̧ão de um filho que perdeu os pais, órfão ou órfã, ou à definição de um cônjuge que perdeu seu companheiro, viúvo ou viúva. A ausência de adjetivo para a morte violenta de um filho alimenta a dúvida radical, como reflete Butler (2004: 21-23), sobre quem é esse "eu", que passou a existir sem 
"você". O limiar do luto opera sobre a complexa relação da linguagem comum e da "linguagem da violência" como da existência de mães e pais "sem nomes"15.

O inominável se insere após a morte do ente na vida dessas famílias. A linguagem da "sociabilidade violenta" não nomeia pais e mães. As reelaborações da violência, os rituais fúnebres e os trânsitos pelos hospitais, delegacias e instâncias da justiça não os reinserem nas definições das identidades possíveis. Uma inexistência e uma violência pela linguagem.

A história de vida narrada pelos próprios familiares sobre seus entes e sobre o grupo familiar, como no depoimento de Ana, demarca essa ausência:

Quando vocêcria um filho e você solta, você sabe que o mundo não tem coisas muito boas a oferecer. Aí você fica "deu meia noite", "deu uma" e seu filho não chegou, aí você não dorme preocupada. Você não dorme com o receio de ter acontecido algo, mas não foi o que aconteceu com eles. (...) Eu chegava e ele estava no videogame ou no computador, entendeu? Ee é muito difícil você conviver com essa dor. É muito difícil porque eu tinha planos para os meus filhos, entendeu? Eu tinha expectativa de vida e, hoje em dia, eu não tenho mais expectativa de vida...

Esse relato sobre a vítima lembra aspectos de um cotidiano dessas famílias que têm como contraponto à "sociabilidade violenta" da cidade do Rio de Janeiro. Ao falar de seus entes e suas rotinas, eles reconstroem uma história de vida que não considerava a possibilidade de interrupção pela violência. Diante dos números de mortes violentas na cidade, a visão de mundo que exclui a violência da rotina de seus cidadãos pode ser considerada um aspecto da "ilusão biográfica", conceituada por Bourdieu (1986). Essa ilusão tende a identificar no mundo social uma normalidade ou uma construção previsível de uma história de vida "bem construída". Como pessoas inocentes, eles deveriam cumprir seus planos de vida. Como analisa Bourdieu (1996: 75):

Sem dúvida, temos o direito de supor que a narrativa autobiográfica inspira-se sempre, ao menos em parte, na preocupação de atribuir sentido, de encontrar a razão, de descobrir uma lógica ao mesmo tempo retrospectiva e perspectiva, uma consistência e uma constância, de estabelecer relações inteligíveis, como a do efeito com a causa eficiente, entre estados sucessivos, constituídos como etapas de um desenvolvimento necessário.

Essa lógica de uma história de vida com etapas sucessivas é regida pela noção de controle e autocontrole do curso de vida na sociedade ocidental contemporânea, na qual a morte é levada para os bastidores da vida social (Elias, 2001: 14). As supostas negação e exclusão, tanto da violência quanto da morte das relações
15 Refiro-me também à coluna da Revista O Clobo de 3 de fevereiro de 2013, p. 6 , que cita a página do Facebook, chamada "Mães sem nome", criada por Márcia Noleto, que perdeu sua filha de 20 anos em um acidente. 
sociais, legitimam as causas coletivas como consequência de uma morte inaceitável. Ao mesmo tempo, compara-se as mortes violentas com "perdas aceitas" e menos dolorosas, seja por uma morte natural, seja por motivo de doença, que são concebidas como uma etapa natural do curso da vida.

Nesse sentido, vale agora retomar o questionamento inicial sobre como se cumpririam as etapas futuras de uma "etnografia em contextos de violência" em meio à permanência da mesma e se ultrapassaríamos as fronteiras de uma "ilusão etnográfica".

A apresentação de movimentos como etapas do processo de pesquisa destaca as características relevantes de cada um deles, mas vale pontuar que há um fluxo dinâmico e não-linear em que é possível percebê-los em diferentes momentos. Para isso, o Movimento Zero mais que reelaborar os passos iniciais dessa pesquisa, e talvez de outras, inscreve todos (e muito provavelmente $o$ leitor) como parte dessa sociabilidade violenta, pois, segundo Silva (2016:194), a violência urbana não "destrói ou substitui os padrões convencionais de sociabilida$d e$ ", mas convive - "por contiguidade e não como 'luta de valores'-entre os dois padrões" (grifo nosso).

\section{MOVIMENTO ZERO...}

Se o interesse inicial, relatado para André Azevedo, era o de compreender como as notícias de violência do Rio de Janeiro foram produzidas, ao me aproximar dos "personagens dessas notícias" - fotojornalistas, familiares de vítimas e ativistas de movimentos contra violência - percebi a existência de diferentes tons de um "anthropological blues".

Dentre eles, a complexidade das identidades construídas e reconstruídas em uma etnografia com familiares de vítimas tanto como categoria da prática quanto como categoria de análise, discutidas por Brubaker e Cooper (2000). Na primeira, acionam identidades unificadas e coesas em prol de uma política de reconhecimento, enquanto a segunda se elabora a partir da primeira em busca de uma coerência de sentido para o outro, para si e para produção de conhecimento antropológico.

Os números recentes de homicídios (janeiro, fevereiro, março e abril de 2016) no Estado do Rio de Janeiro continuam a denunciar a distância de um "out of the blue" da violência urbana. Na pesquisa que o Instituto de Segurança Pública compara a letalidade violenta com os mesmos meses de 2015, na rubrica "Homicídio Doloso" houve aumento de 15,4\% de um ano para outro $(1.486$ em 2015; 1.715 em 2016) (Nascimento, 2016).

Durante o meu primeiro contato com o campo, ninguém foi morto diretamente pela violência, mas interlocutores e informantes reivindicaram o reco- 
nhecimento identitário de vítimas secundárias da morte violenta pela ativação da memória de suas biografias, que sofreram as consequências da "violência original" e que, em alguns casos, levaram à morte. Alguns familiares de Júlio Baptista, que eu gostaria de ter entrevistado, morreram antes do nosso segundo encontro e são considerados vítimas (secundárias) do assassino de Júlio. A irmã foi diagnosticada com câncer e, após uma sessão de quimioterapia, sofreu um infarto. Um mês depois, a mãe faleceu.

A morte de uma amiga, não por uma violência urbana, mas por um acidente que poderia ter sido evitado, foi amplamente noticiada pela mídia. Yo, como era conhecida, foi uma das vítimas do edifício que desabou no Centro do Rio de Janeiro, na noite de 25 de fevereiro de 2012. Soube da queda do prédio pelo telejornal da manhã. Pouco depois, recebi um telefonema, avisando que ela era uma das vítimas, mas nenhum dos seus pertences, nem seu corpo, foi encontrado e o caso foi abandonado.

Diferente de Foote-Whyte (2005) que foi avisado por Doc de que não deveria se comportar como um deles, uma etnografia sobre violência em meio à sociabilidade violenta pode não nos deixar opção. Meses depois, contei o fato para Patrícia Oliveira, coordenadora da Rede Contra Violência, que disse: "Agora você sabe o que os familiares de desaparecidos passam. É assim mesmo que as pessoas ficam... Com as mães é um pouco pior." "De forma inevitável, "I got the blues" ainda em campo com um longo trabalho de análise e escrita para fazer.

16 Sobre familiares de vitimas de desaparecidos, ver Araújo (2012)

Aline Gama é antropóloga. Desenvolve pesquisas nas áreas de antropologia da família, fotojornalismo e violência com abordagem da antropologia visual.

Clarice Peixoto é antropóloga, professora associada da Universidade do Estado Rio de Janeiro. Atua nos campos da antropologia da família e do envelhecimento, e da antropologia visual.

\section{REFERÊNCIAS BIBLIOGRÁFICAS}

ALMEIDA, Aline Gama de

2013 In memoriam: imagens do sofrimento dos familiares de vítimas da violência no Rio de Janeiro. Rio de Janeiro, tese de doutorado, Universidade do Estado do Rio de Janeiro. 
ARAÚjO, Fábio Alves

2015 Das "técnicas" de fazer desaparecer corpos. Rio de Janeiro, Lamparina.

ARIĖS, Philippe

1977 História da morte no Ocidente: da Idade Média aos nossos dias. Rio de Janeiro, Francisco Alves Editora.

BEAUVOIR, Simone

1967 O segundo sexo. São Paulo, Difusão européia do livro.

BOLTANSKI, LUC

1993 La Souffrance à distance. Morale humanitaire, médias et politique. Paris, Éditions Métaillé.

1990 L'Amour et la justice comme compétences: trois essais de sociologie de l'action. Paris, Éditions Métaillé.

BOTT, Elizabeth

1976 Família e rede social. Rio de Janeiro, Francisco Alves.

BOURDIEU, Pierre

1996 Razões práticas: sobre a teoria da ação. Campinas, Ed. Papirus.

BLUMER, Herbert

1986 Symbolic Interactionism: Perspective and Method. Berkeley, University of California Press.

BRUBAKER, Rogers e COOPER, Frederick

2000 "Beyond 'Identity". Theory and Society, v.29:1-47.

BUTLER, Judith

2004 Precarious Life: The Powers of Mourning and Violence. Londres/Nova York, Verso.

CARSTEN, Janet

2004 After Kinship. Cambridge, Cambridge University Press.

CLIFFORD, James e MARCUS, George E.

1986 Writing Culture: The Poetics and Politics of Ethnography.

Berkeley, University of California Press. 
COELHO, Maria Claudia (org.)

2013 Estudos sobre interação. Textos Escolhidos. Rio de Janeiro, EdUER].

COMERFORD, John

1999 Fazendo a luta. Rio de Janeiro, Relume-Dumará.

DAMATTA, Roberto

1978 "O ofício de etnólogo, ou como ter 'anthropological blues". In NUNES, Edson (org.). A aventura sociológica. Rio de Janeiro, Zahar, pp. 23-35.

DAS, Veena

2007 Life and Words: Violence and the Descent into the Ordinary. Berkeley, University of California Press.

ELIAS, Norbert

2001 Solidão dos moribundos. Rio de Janeiro, Jorge Zahar Ed.

FAVRET-SAADA, Jeanne

2005 "Ser afetado". Caderno de Campo, n.13: 155-161.

FARIAS, Juliana

2014 Governo de mortes. Uma etnografia da gestão de populações de favelas no Rio de Janeiro. Rio de Janeiro, tese de doutorado, Universidade Federal do Rio de Janeiro.

FERREIRA, Letícia Carvalho de Mesquita

2011 Uma etnografia para muitas ausências. O desaparecimento de pessoas como ocorrência policial e problema social. Rio de Janeiro, tese de doutorado, Universidade Federal do Rio de Janeiro.

FOOTE-WHYTE, William

2005 Sociedade da esquina: a estrutura social de uma área urbana pobre e degredada. Rio de Janeiro, Jorge Zahar.

GEERTZ, Clifford

2002 Obras e vidas: o antropólogo como autor. Rio de Janeiro, Editora UFR].

2001 Nova luz sobre a antropologia. Rio de Janeiro, Jorge Zahar Ed. 
COFFMAN, Erving

1988 Estigma: notas sobre a manipulação da identidade deteriorada. Rio de Janeiro, Editora Guanabara.

1981 Forms of Talk. Philadelphia, University of Pennsylvania Press.

1975 A representação do eu na vida cotidiana. Petrópolis, Vozes.

HALL, Stuart

2000 A identidade cultural na pós-modernidade. Rio de Janeiro, DP\&A.

HALL, Stuart e GAY, Paul du

2003 Cuestiones de identidad cultural. Buenos Aires, Amorrotu.

HINE, Christine

2000 Virtual Ethnography. Londres, Sage.

JIMENO, Myriam

2010 "Emoções e política: a vítima e a construção de comunidades emocionais". MANA, v.16, n.1: 99-121.

LACE, Nilson

1982 Ideologia e técnica da notícia. Petrópolis, Vozes.

MAUSS, Marcel

1980 "A expressão obrigatória dos sentimentos". In FICUEIRA, Sérvulo Augusto (org.). Psicanálise e ciências sociais. Rio de Janeiro, Francisco Alves, pp. 56-63.

MOREIRA LEITE, Miriam

2001 Retratos de família: leitura da fotografia histórica. São

Paulo, Editora da Universidade de São Paulo.

NASCIMENTO, Karina

2016 ISP divulga números de abril de 2016. Disponível em: http://www.isp.ri.gov.br/Noticias.asp?ident=354

PAIVA, Raquel e SODRÉ, Muniz

2005 "Sobre o facto e o acontecimento". Revista de Comunicação, Cultura e Educação, v.6: 95-100.

RICOEUR, Paul

2007 A memória, a história, o esquecimento. Campinas, SP, Editora UNICAMP. 
ROCHA, Ana Luiza Carvalho da e ECKERT, Cornelia

1998 "A interioridade da experiência temporal do antropólogo como condição da produção etnográfica". Revista de Antropologia, v. 41, n. 2: 107-136.

SAHLINS, Marshall

2013 What kinship is and is not. Chicago e Londres, The University of Chicago Press.

SARDAN, Jean-Pierre Olivier de

1996 "La Violence faite aux données". Enquête [En ligne], v. 3: 31-59.

SILVA, Luiz Antonio Machado da.

2016 Fazendo a cidade: trabalho, moradia e vida local entre as camadas populares urbanas. Rio de Janeiro, Mórula.

2011 "Polícia e violência urbana em uma cidade brasileira".

Etnográfica [Online], v. 15, n. 1: 67-82.

SOARES, Cláucio Ary Dillon; MIRANDA, Dayse e BORGES, Doriam

2006 As vítimas ocultas da violência na cidade do Rio de

Janeiro. Rio de Janeiro, Civilização Brasileira.

SODRÉ, Muniz e FERRARI, Maria Helena

1982 Técnica de redação-O texto nos meios de informação.

Rio de Janeiro, Francisco Alves.

SOUZA, Jorge Pedro de

1999 As notícias e os seus efeitos. As "teorias" do jornalismo e dos efeitos sociais dos media jornalísticos. Biblioteca On-Line de Ciências da Comunicação, 1999. Disponível em: http://www.bocc.ubi.pt/ pag/_texto.php?html2=sousa-pedro-jorge-noticias-efeitos.html

VELHO, Gilberto

1978 "Observando o familiar". In: NUNES, Edson (org.) A aventura sociológica. Rio de Janeiro, Zahar, pp. 36-46.

VIANNA, Adriana e FARIAS, Juliana

2011 "A guerra das mães: dor e política em situações de violência institucional". Cadernos Pagu, n. 37. 
ARTIGo| Aline Gama e Clarice Peixoto | Identidades em

movimento: uma etnografia em contexto de violência

VIVEIROS DE CASTRO, Eduardo

2002 "O nativo relativo". Mana, v. 8 n. 1: 113-148.

YOUNG, Iris Marion

2005 On Female Body Experience. "Throwing Like a Cirl" and

Other Essays. Nova York, Oxford University Press.

WIEVIORKA, Michel

2005 La Violence. Paris, Hachette Littératures. 
Identities on the Move: An Ethnography in the Violence Context

\section{ABSTRACT}

The paper analyzes some movements on which the identities in the research with families of victims of violence in Rio de Janeiro, trigger codes of ethical and moral conduct. From the participant observation, interviews and other information obtained in field, all these, done between 2009 and 2013, we have discussed the inter-subjective relationship of the anthropologist and the victim's family based in the contemporary debate about identity and alterity. In the field, these identities are elaborated in order to overcome the individual suffering of the victims' families in favor of the collective causes, but it is not only this, what becomes a collective struggle against violence from the news media. Considering the appropriate degrees of involvement, the suffering of the family triggers, others as researchers, readers and institutions that enroll in a language and in a violent sociability. However, inside this identity movement, in a limit situation, the emergence of denials and "double" subject / agent of urban violence can be seen.

\section{KEYWORDS}

Identity, Urban

Violence, Victims

Family, Urban

Anthropology

Recebido em 1 de agosto de 2016. Aceito em 17 de março de 2017. 